\title{
Campos de BATAlHa intelectuAl E nOVOS PARADIGMAS DO PENSAMENTO AFRICANO
}

BARBOSA, Muryatan. A razão africana: breve história do pensamento africano contemporâneo. São Paulo: Todavia, 2020. 216 p.

$\mathbf{N}_{\text {ão tem sido comum na historio- }}$ grafia brasileira escrever sínteses que esclareçam temas e questões da contemporaneidade da África. Muryatan Barbosa enfrenta o desafio a começar pelo título da obra aqui resenhada, A razão africana, que talvez seja correto definir como a capacidade intelectual e moral que se realiza em circunstâncias históricas e contextos epistemológicos específicos. E para compreender a natureza e o sentido da razão africana, o autor elaborou um grande retábulo com as principais ideias de um número significativo de intelectuais africanos e africanistas.

O historiador ressalta que, marcados por ambiguidades e ambivalências de linguagem, os escritos analisados permitem observar que este pensamento plural e interdisciplinar, além de conter novas categorias e conceitos, configuraram uma perspectiva analítica particular, própria de novos paradigmas. E, ao condensar a múltipla e complexa relação entre passado e presente em diversas circunstâncias históricas e contextos epistemológicos, abriu as abas do político e assinalou a importância das configurações intelectuais dissidentes. Também revelou que aos poucos as estruturas discursivas deixaram transparecer a diminuição da influência do contexto epistemológico ocidental presentes na historiografia e na antropologia, que as tornavam tributárias da noção biológica de raça, quase sempre 
associada à supremacia branca e ao idioma "proto-indo-europeu".

Note-se que a violência epistêmica presente no modelo de cultura imperial trabalha com a noção de diferença com sentidos distintos e complementares, construindo uma África como lugar de atraso, fundada em uma tradição estática, fixa e a-histórica, contraposta à Europa enquanto espaço universal da civilização. Legitima-se, assim, a aculturação do Outro definido como exótico, bárbaro, degenerado, inferior e guiado pelo instinto, subtraindo-lhe o direito à iniciativa histórica, à produção de cultura, a uma personalidade própria e suas racionalidades.

Em suma, esta filiação epistemológica construiu mundos ontologicamente distintos, que formavam uma totalidade antagônica, com suas geografias sobrepostas e histórias entrelaçadas, ${ }^{1}$ com nítidas marcas das políticas da diferença que levaram ao grande número de resistências por

1 Estas assertivas apontam para a situação colonial, ideia básica de Frantz Fanon, Os condenados da terra, $2^{\mathrm{a}}$ ed., Rio de Janeiro: Civilização Brasileira, 1979; e mais tarde, em outra chave analítica, sistematicamente trabalhadas por Edward Said, Cultura e Imperialismo, São Paulo: Companhia das Letras, 1995. parte dos nativos africanos. Eram explicações com estreitas ligações ideológicas, que oscilavam entre a passividade dos nativos e a brutalidade dos seus instintos guerreiros. Estas considerações imperiais articulavam conhecimento e poder com forte intercâmbio entre ciência colonial e sentido imaginativo, encobrindo a violência estrutural presente na extrema desigualdade de poder, na degradação e na humilhação contrapostas pelas diferentes formas de resistência.

No plano intelectual, a resistência ao moderno imperialismo europeu ocorrida desde o século XIX se fez com novas narrativas históricas que, embora informadas por teorias raciais, estruturas conceituais e de análise eurocêntricas, tiveram o olhar atento às questões que a história colocava à teoria. E a concretude imposta pelos constrangimentos levou os intelectuais africanos e afro-diaspóricos a perguntar: o que é ser africano? As respostas tiveram em comum a luta pelo direito à diferença, provocando esgarçamentos no paradigma classificatório formulado pelo Ocidente, a revelar as bases do pensamento africano. 
Para compreender a natureza e o sentido da razão africana, Muryatan Barbosa revisitou um número significativo de obras de africanistas anticoloniais com perspectivas analíticas particulares, no intuito de compreender a formação e a sequência de três grandes paradigmas: "a personalidade africana”, “o reino político” e o "autodesenvolvimento” . Proposta ousada, que permitiu ao autor apresentar uma reunião de ideias que pedem menos para serem reiteradas do que para instigar a controvérsia e o debate. E começo minhas considerações delimitando o que acredito ser absolutamente essencial: as implicações teóricas e políticas que $A$ razão africana enseja.

Há um certo consenso, historicamente compreensível, de que o processo de construção da razão africana na modernidade - constituída por discursos africanistas e os efeitos de seus desdobramentos - tiveram por marco as obras de Edward Wilmot Blyden (1832-1912). Intelectual e ativista, assim como outros caribenhos, africanos e afro-estadunidenses, ele sofreu influência do pensamento racialista da Europa e dos Estados Unidos. Porém, se desviou do biologismo e construiu uma concepção histórica original da categoria raça. Este afastamento da ficção das positividades do colonial esteve marcado por críticas à imposição do cristianismo e ao ensino da língua do colonizador em nome dos imperativos políticos para educar os africanos e conduzi-los ao progresso moral e intelectual. A visão de Blyden permitiu-lhe descerrar os véus que encobriam o objetivo das metrópoles de assegurar o controle e a estabilidade da dominação imperial. E ao negar a relação entre multilinguismo e desordem social passou a defender, de forma inédita, a introdução do estudo do árabe e de línguas africanas no currículo escolar. ${ }^{2}$

Seu discurso pan-africano acentuou a ideia - compartilhada com Alexander Crummell e retomada por Marcus Garvey (1887-1940) e W. E. B. Du Bois (1868-1963) - de que a Libéria, por sua história e tradições,

2 Este é um tema teórica e politicamente complexo, expresso nos anos 1960 por várias lideranças anticoloniais, sobretudo Julius Nyerere e seu desejo de tornar o suaíli língua nacional na Tanzânia. Foi tema que desafiou intelectuais como o queniano Ngugi wa Thiong'o, que conecta políticas da língua e identidades nacionais, negando que o multilinguismo seja em si uma ameaça permanente à ordem. 
teria de ser conduzida por negros que por seu "instinto e gênio" teriam de se deslocar da América para a terra de seus antepassados, participando ativamente da construção do primeiro Estado independente moderno africano, com potencial para se difundir por toda a África Ocidental e dali se irradiar para todo o continente. E não tardou a considerar que os afro-americanos deveriam ser civilizados pelos nativos e não o inverso.

A visão de Blyden teve uma espantosa importância em aspectos que surgiram repetidas vezes, como o relativo à educação, tida como lugar privilegiado em termos políticos e culturais, moldando os contornos da retórica militante da autonomia. Este foi um ponto retomado por Casely Hayford, natural da Costa do Ouro (1866-1930), jornalista e advogado formado na Inglaterra, que propôs a criação de uma educação africana, “com currículo e instituições próprias”, voltada para preparar os africanos para um projeto de autogestão. Nessa perspectiva destaca-se atuação do ganense James Aggrey (1875-1927), pioneiro no incentivo do ensino de história, geografia, agronomia e direito consuetudinário africanos, contrapondo-se ao europeísmo que dominava a educação nas colônias. Esse tipo de preocupação formou um corpo teórico e prático que, ao longo do século $\mathrm{XX}$, foi usado como arma para desenvolver uma consciência crítica a respeito das configurações do poder colonial, permanecendo nos primeiros vinte anos do século XXI como uma das questões centrais, segundo o filósofo, acadêmico e político beninense Paulin Hountondji. ${ }^{3}$

De outra parte, ao incluir a contribuição de Henry S. Wilson, o historiador Muryatan Barbosa destaca que a estrutura que vincula entre si as obras analisadas no seu livro gira em torno da ideia de "personalidade africana" enquanto fruto de determinações qualitativas, como "família, vida coletiva, uso comum da terra e da água, regulação das funções sociais” (p. 19), sublinhando o protagonismo africano. Aponta, pois, a "personalidade africana” como uma categoria positiva seminal oposta à imagem e ao sentimento de inferioridade entranhados no negro africano e afro-diaspórico.

3 Paulin Hountondji, "Conhecimento de África, conhecimento de africanos: duas perspectivas sobre os Estudos Africanos”, Revista Crítica de Ciências Sociais, n. 80 (2008), pp. 149-160. 
E lembra que foi com essa categoria que Blyden antecipou por três décadas a de "novo negro", cunhada pelo afro-estadunidense Alain Locke (1885-1954) que deu nome, nos anos 1920, ao New Black Movement. ${ }^{4}$ Retomada nos anos 1950 pelo martinicano Aimé Césaire (1913-2008), no Caderno de retorno ao país natal (1956), também foi central nas ideias do senegalês Léopold Senghor (19062001), que, em articulação direta com a ideia de negritude, a definiu como o conjunto de valores culturais próprio da tradição negra, além de ecoar no pensamento do ganense Kwame Nkrumah (1909-1972), em African Personality (1963).

À vontade pelo seu domínio da bibliografia e com uma análise textual detalhada, Barbosa apresenta ainda o pensamento de outros intelectuais e ativistas comprometidos com a severa negação que corta transversalmente as estruturas de discriminação racial, social, econômica e política, influindo de forma decisiva na segregação mental. Desenha-se, assim, um novo

4 Alain Locke, "The New Negro" in Alain Locke (org.), The New Negro: An Interpretation (Nova York: Atheneum, 1969 [1925]), pp. 3-16. padrão: o de voltar-se para uma África africana. Nessa perspectiva, dentre os autores analisados pelo historiador, destaco o estadunidense W. E. B. Du Bois (1868-1963) e o jamaicano Marcus Garvey (1887-1940).

Sociólogo e historiador, Du Bois refletiu sobre a igualdade racial, entendendo que a barreira da cor era o grande problema do século XX e, como ativista, se engajou nos movimentos contra as medidas segregacionistas e as leis de exceção nos Estados Unidos, o apartheid na então África do Sul e a prática jurídica e administrativa da situação colonial em África. Ao reconhecer o desejo de emancipação, libertação e reconquista da dignidade humana, passou a convocar os descendentes de africanos para viver na Libéria, apresentada como território cujas condições de autonomia eram consideradas efetivas, prefigurando o nacionalismo continental africano. E se como ativista esteve alerta à degradação dos negros espalhados pelo mundo, como intelectual Du Bois esclareceu que a diáspora negra e a África estavam unidas por práticas culturais e anseios comuns pela conquista da igualdade e da cidadania. 
Contudo, há um certo consenso de que foi Garvey quem articulou a resistência e a oposição à assimilação forçada, à discriminação e à segregação raciais, apresentando-as como fundamentos para o Pan-africanismo enquanto movimento transcontinental. Líder carismático, com seu discurso libertário percorreu a Jamaica, a Inglaterra, os Estados Unidos e países da África, enfatizando a modernização e a emancipação como os principais objetivos da sua prática política. E com forte acento messiânico proclamou a "redenção dos negros", encorajando-os a seguirem o destino de viver na África, com a missão de emancipá-la e modernizá-la sob o lema “A África para os africanos!”

Logo se vê que o tema dos trânsitos e das itinerâncias de ideias, homens e escritos indica múltiplas formas de deslocamento presentes na modernidade colonial. Este ponto é imprescindível para entendermos o que representou Paris na década de 1940, onde se intensificou a atmosfera de intensas trocas intelectuais pontuadas pelas elaborações críticas que alimentaram a afirmação da historicidade e do dinamismo cultural da África. Desta maneira foi possível entender a redescoberta do passado, da tradição historicamente renovada e do dinamismo interno de culturas plurais. Tais aspectos formavam a base de um processo rememorado em artigos publicados na Présence Africaine: revue culturelle du monde noir - fundada em 1947 -, criando condições para que fosse construída uma nova constelação textual que abriu espaço para a emergência da Négritude e de outras textualidades intelectuais de africanos, antilhanos, norte-americanos e franceses, ensejando uma nova perspectiva anti

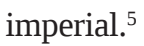

Revisitar esse movimento significa compreender que a exaltação do ser e do viver próprio do negro pressupunha uma ruptura com a cultura branca desde as suas raízes para que a alma negra pudesse renascer. Razão mais que suficiente para reafirmar a identidade e a legitimidade do negro, ao mesmo tempo em que se abria espaço para que se constituísse um grupo social militante, com força para descartar a suposta inferioridade da razão negra. Esta remodelação

5 Uso a palavra Négritude em francês e em caixa alta quando se tratar do movimento da Négritude. 
profunda implicou em integrar a positividade histórica e cultural em uma definição do ser africano que passou a ser patrimônio cultural e intelectual dos negros em todo o mundo.

Nesse movimento de resistência cultural descolonizante, porém, havia ambiguidades, algumas alimentadas pela oposição entre espiritualidade e racionalidade, como exposta no artigo "O contributo do homem negro", de Léopold Sedar Senghor (1906-2001). ${ }^{6}$ Nele o poeta e político senegalês opôs espiritualidade (dos africanos) e racionalidade (dos europeus), posicionamento compartilhado, entre outros, pelo poeta martinicano Aimé Césaire, que dele se desvencilhou poucos anos mais tarde. Sua superação exigiu que a razão norteasse uma nova gramática discursiva, tirando os saberes tradicionais da fixidez que os colocava na marginalidade para redefini-los, com ênfase, no pluralismo e no dinamismo das experiências ancestrais.

6 Léopold Sédar Senghor, "O contributo do homem negro” in Manuela Ribeiro Sanches (org.), Malhas que os impérios tecem. Textos anticoloniais, contextos pós-coloniais (Lisboa: Edições 70, 2011), pp. 73-92.
Recorro a Césaire porque trouxe à tona, como poucos, a complexidade histórica e cultural nos anos 1950 e 1960, insistindo em descolonizar o conhecimento histórico com acento em dinâmicas históricas e culturais específicas - no caso, da Martinica - para definir negritude no seu célebre poema Caderno de regresso ao país natal. Ao reunir símbolos, imagens figurativas e diferentes expressões da vida africana, e recuperar os atributos da personalidade negra, ele negou com veemência o caráter pré-lógico imputado ao africano. Nessa mesma chave de análise ressaltou as aspirações e valores que remetiam ao resgate da pátria da qual os negros foram “desterrados”, ou seja, a África, deixando ressoar com vigor a centralidade do nacionalismo.

De outra parte, esboçou a dimensão educadora da arte popular e o ideal de uma "cultura viva”, sugerindo a "experiência poética" como meio de o negro tomar consciência de si mesmo. Nesse impulso, a contenda para transpor os limites que acompanhavam a raça levou-o à construção de um sentimento vivo, que transpôs a Martinica, abrangendo todos os países 
que estavam sob o domínio do imperialismo cultural.

Não foi menor o impacto do pensamento de Senghor. Este político e escritor tomou um caminho próprio levando em conta o humanismo e o existencialismo, o que tornou o tema da negritude ainda mais controverso e complexo. ${ }^{7}$ Fato é que este, como outros pontos, eram indissociáveis da tomada de consciência histórica e social decisiva para a construção de um novo paradigma emancipatório marcado pelo primado da política, como reflete Barbosa na segunda parte do seu livro, "O reino político". Reconheço a legitimidade do desafio que o autor traz como forte estímulo à reflexão sobre a construção da política de unidade continental enquanto processo que articula circunstâncias sócio-históricas e contextos epistemológicos.

Essa observação reconduz a considerações sobre os três principais marcos dos caminhos de renovação do pensamento africano e, empiricamente, para as conjunturas marcadas pela mobilização política: o período entre guerras, o V Congresso

7 Léopold Sédar Senghor, Liberté I Négritude et Humanisme, Paris: Éditions Le Seuil, 1964.
Pan-Africano e o socialismo africano. No que diz respeito ao período entre 1918 e 1939, sabe-se que o ambiente social e político endógeno se tornou cada vez mais explosivo, ensejando reflexões capazes de dar conta das especificidades históricas com propostas políticas diversas, o que permite, ao menos em parte, compreender a incapacidade de conferir unidade ao pensamento africano sobre a emancipação. Por outro lado, a resolução central do V Congresso Pan-africano constitui um marco condenatório do imperialismo, do capitalismo, do colonialismo e do racismo, definindo o confronto e a resistência sistemáticas no âmbito de um processo de tessitura de redes transnacionais e transcontinentais. E não é demais recordar que, naquele momento, os intelectuais militantes temeram um possível descompasso entre ideia e prática políticas, voltando-se para a mobilização das massas no enfrentamento ao império ocidental.

Quanto ao socialismo africano como formação discursiva instrumental da política, desde a segunda metade de 1940 em diante marcou a premência política tornando vital 
arquitetar o presente e com ele o socialismo enquanto construção nacional. Mas houve quem fizesse alarde de suas posições liberacionistas e francamente capitalistas, como o futuro presidente da Costa do Marfim, Félix HouphouëtBoigny (1905-1993). Contudo, as vontades políticas, em um jogo de possibilidades e constrangimentos, deixaram de lado as grandes diferenças ideológicas, mantendo algum grau de coesão para a consecução das independências.

Aliás, a problematização dos contextos de luta por emancipação trouxe para as lideranças africanas o empenho em participar de fóruns transcontinentais de articulação de interesses e solidariedades - como gosto de chamar-, com destaque para a Conferência Afro-Asiática (Bandung, 1955), a I Conferência dos Países Não Alinhados (Belgrado, 1961) e a Conferência Tricontinental de Havana (1966). Neles foram travadas discussões sobre temas cruciais, como a soberania, a unidade e o não-alinhamento que ressurgiram repetidas vezes acrescidos de outros, como o desenvolvimento, a modernização, a via revolucionária e a luta contra o neocolonialismo, com estratégias contendo significativas dimensões utópicas a curto e médio prazo, uma vez que implicavam em mudanças na natureza da economia (de subsistência para de mercado), da política (de sujeição para participação), sociais (das unidades de parentesco alargadas para nucleares) e da ideologia (do sagrado ao secular).

Estes anseios emergiram em muitos momentos, impondo, no espaço desta resenha, elaborar um recorte circunscrito a algumas recomposições presentes nos discursos emancipacionistas. Por isso, sem diminuir a importância dos demais, destaco escritos de George Padmore (1903-1959), Kwame Nkrumah (1909-1972), Nnamdi Azikiwe (1904-1996) e Julius Nyerere (1922-1999), começando por assinalar que nenhum deles escapou do impacto das injunções políticas que os levaram a conceber o socialismo africano com diferentes leituras do marxismo, para considerar o que realmente estava em jogo. Nem por isso as modalidades dos seus discursos deixaram de trazer a "personalidade africana" como categoria reatualizada na construção social da identidade, mesmo que nem sempre de forma explícita.

Essa resistência cultural era animada pela convicção de que a 
África poderia se desenvolver modernizando algumas de suas particularidades históricas e culturais, como o coletivismo, os laços familiares (em particular os de compadrio), a sociabilidade ("conviç̧ões éticas, laços de afeição e mundos compartilhados de significações”) e os compromissos democráticos na prática política (em especial o poder de decisão das chefias locais balizado pela consulta popular). ${ }^{8}$

Convém dizer que a dissonância das ideias acompanhou a escolha das estratégias para afastar qualquer medida neocolonialista que se insinuasse nos países de economia e política mais débeis, pouco capazes de superar situações de crise permanente. Com uma relação um tanto ambígua com o tempo colonial e os poderes administrativos e jurídicos da colonização, e em nome da defesa das soberanias nacionais, foi grande o esforço para combater as vicissitudes

8 Como o critério era sobretudo político e os discursos faziam parte dos debates entre os intelectuais africanos, tomo a liberdade de apresentar entre parênteses e em itálico o que cada aspecto abrangia empiricamente, retomando Kwame Anthony Appiah, Na casa de meu pai: a África na filosofia da cultura, Rio de Janeiro: Contraponto, 1997, p. 223. da balcanização e o aumento da vulnerabilidade dos países africanos. $\mathrm{O}$ que se debatia era como romper radicalmente as relações imperialistas, ensaiando a narrativa da construção da unidade africana como imprescindível para a soberania do continente.

Mas esta não foi uma escolha consensual porque a integração dos países era vista por suas elites como ameaça e o desenrolar dos acontecimentos mostrou diferentes caminhos para a independência nacional e para o pan-africanismo, ainda que por vezes tenham ficado próximos. Para George Padmore, sempre atento aos acontecimentos da conjuntura internacional, o processo de independência indiano, que priorizava as "ações positivas não violentas" - como notabilizado pelo nacionalista anticolonialista Mahatma Gandhi (1869-1948) - deveria ser tomado como modelo para a Costa do Ouro. Em concordância com Padmore, Nkrumah rechaçou a luta armada, preferindo manifestações pontuais, como campanhas educacionais e junto à imprensa, realização de greves, retaliações e boicotes.

Porém, Nkrumah logo se afastou do nacionalismo e do prosseguimento das reformas constitucionais 
e mostrou-se um franco defensor da federação de países autogovernados, composta primeiro por países da África Ocidental, seguida por federações das demais regiões e depois reunidas nos Estados Unidos da África. E na busca por legitimidade pensou a unidade e a integração africanas em relação aos laços do sistema social, isto é, “as tradições, a história, ao meio ambiente e ao padrão comunal da sociedade" (p. 72). E ao englobar distintas conexões transnacionais, enfatizou a unidade como a única forma de a África construir uma soberania efetiva, com poderes supranacionais eficazes para sustar as investidas e os avanços do neocolonialismo, como mostra Muryatan Barbosa.

O problema é que as lideranças, ao menos abertamente, não divergiam quanto ao diagnóstico histórico-social que fundamentava a escolha pela unidade africana. No entanto, concebiam-na com natureza e sentidos diferentes e discordavam das estratégias para construí-la. E era nítida a desconfiança em relação à proposta de unificação política lançada por Nkrumah de fazer da África uma só nação, com um governo central, uma linha política única e poder de decisão nos setores chaves da economia e da política, avaliando-a como um primeiro passo para o estabelecimento de um colonialismo interno.

Comooprocessohistóricoécontraditório e os países africanos feitos de especificidades, as concepções sobre a unidade africana foram várias e diferentes. O nigeriano Nnamdi Azikiwe (1904-1996), por exemplo, contrário à unidade africana rápida e maximalista, ponderou que a integração haveria de ser gradual, pautada em medidas econômicas e sociais e conduzida pelos povos africanos e não pela ação dos seus líderes. Já o tanzaniano Julius Nyerere sustentava que a consecução da unidade africana pressupunha o desenvolvimento de uma consciência entrelaçada a uma lealdade africana. Defendia ainda que seria de competência dos pan-africanistas cuidar da liberdade e do desenvolvimento de cada nação africana, advertindo que empiricamente esses valores poderiam ser conflitantes.

Fato é que as divergências entre nacionalismo e unidade pan-africanista, potencializadas por disputas pessoais, levaram à polarização, ensejando a criação de dois grupos opostos, o de Casablanca (1961) o de 
Monróvia (1962). E foi graças à intermediação do ministro das Relações Exteriores da Etiópia que se tornou possível reuni-los para a fundação da Organização da Unidade Africana (OUA) - em Adis Abeba, no ano de 1963 -, ocasião em que se decidiu manter as fronteiras coloniais e estabelecer a integralidade territorial, sem descurar da unidade africana. Parece certo que foram anos marcados por incertezas, reatualizando questões que ficaram longe de ser encaminhadas de modo satisfatório, como aponta Muryatan Barbosa (pp. 83-86).

Falando de forma clara, a maioria desses países, embora independentes, mantinha ligações de ordem econômica, política e militar com poderes externos à África. Para compreender a complexidade dessas vicissitudes, os intelectuais e ativistas africanos recorreram ao marxismo heterodoxo, pluralista, com limites indefinidos e, cada qual ao seu modo, concebeu a história, a revolução, a soberania, o partido único, o estado e os sujeitos da construção da cultura nacional e da nação. E para mudar a realidade africana salientaram a relevância da articulação entre teoria e prática emancipadoras.
Nesse contexto torna-se particularmente compreensível que Frantz Fanon (1925-1961) tivesse perguntado: “Quem somos nós?”, "Por que estamos assim?”. Estas questões integraram um pensamento que incidia sobre os processos históricos que levaram a um ambiente revolucionário radical, sendo os camponeses (alternativa para a quase ausência do proletariado urbano) os sujeitos históricos que poriam em movimento uma luta pela conquista efetiva da terra e, sobretudo, o restabelecimento da dignidade humana. Significava também conferir um realce particular à cultura nacional enquanto força aglutinadora na guerra de libertação.

De outra parte, Amílcar Cabral (1924-1973) sintetizou suas preocupações centrais perguntando: "quem somos no desconcerto planetário e que futuro para esta humanidade?” A procura por erigir uma nova sociedade levou Cabral, como teórico e político, a enfatizar as identidades e o direito às singularidades como categorias históricas que se reatualizavam, priorizando a etnicidade, a geografia do local e a centralidade da cultura e da nação enquanto construções simbólicas plurais, produzidas 
durante o processo permanente da guerra de libertação. E ao seu jeito tornou a unidade na diversidade um paradigma e apresentou-a com diferentes acepções: como síntese da cultura dos diferentes povos da Guiné; união de dois territórios geográfica e historicamente distintos, como eram Cabo Verde e Guiné; associação dos países sob a dominação de Portugal na África e na Ásia; e a união dos representantes africanos - em algumas ocasiões incluindo lideranças asiáticas e latino-americanas em torno de uma pluralidade de questões políticas sobre a autodeterminação. Este ponto é fundamental, sobretudo em vista da natureza histórico-social da unidade que incorporava a luta.

Outro ponto que merece destaque é o relativo ao papel do intelectual como representante da nação, devendo se tornar povo e ser o seu porta voz, com uma lógica de pensamento que apresentava o popular e o nacional como dois lados de uma mesma moeda. E nesta lógica caberia um lugar central para conceber a revolução nacional que, no momento seguinte à independência, seria completada pela revolução social que pressupunha desenvolvimento e modernização.

Não por mero acaso estes foram temas extremamente controversos, uma vez que falar de desenvolvimento significava reiterar escolhas políticas sobre a natureza do Estado, seu grau de verticalização e de centralização, conforme as orientações do partido único. Significava controlar as manifestações reivindicatórias das diferentes camadas da população canalizando-as para as organizações de massas. E significava, sobretudo, questionar o projeto real que predominou nos movimentos de independência, se gradualista ou revolucionário, e mesmo em relação a estes eram avaliadas suas proximidades ou afastamentos do marxismo-leninismo, como atestam, até o final da década de 1980, as cartas constitucionais de numerosos países como, por exemplo, Angola, Moçambique, Cabo Verde e Guiné Bissau.

Mas estas disputas pela "verdadeira independência” ganharam novas abordagens e práticas, incluindo conceitos e estratégias com os quais foi sendo construído o paradigma do "autodesenvolvimento" - o terceiro 
momento apresentado em A Razão Africana. Sob as muitas sequelas da crise econômica dos anos 1970 e a crescente marginalização das sociedades africanas, as críticas aos modelos de desenvolvimento exógeno tornaram evidentes o fundamento violento que lhe é próprio. $\mathrm{E}$ não tardou que a crítica insistisse que se fazia absolutamente imprescindível construir um corpo de conhecimento a partir das necessidades e interesses da África e de seus povos. Impôs-se uma autocrítica das Ciências Humanas feita por africanos e a recuperação do poder criativo da razão africana, com liberdade para expor a positividade das interfaces entre o conjunto de conhecimentos teóricos e o "saber fazer".

Esse embate está no centro das preocupações epistêmicas de Muryatan Barbosa, que se dedica em A Razão Africana a tratar dos temas apresentados com uma abordagem dialética materialista, ultrapassando o mero historicismo ou o empirismo simplório. E ao priorizar a análise das transformações paradigmáticas e as dinâmicas das práticas políticas, com uma linguagem precisa e elegante, faz desta uma obra de leitura incontornável.

\section{Leila Leite Hernandez $\boldsymbol{Z}$ \\ Universidade de São Paulo}

doi: 10.9771/aa.v0i63.44057 